\title{
Numerical Study of Viscous Fluid Flows in a Kenics Static Mixer
}

\author{
Cherif BELHOUT*, Mohamed BOUZIT**, Brahim MENACER***, Youcef KAMLA****, \\ Houari AMEUR****** \\ ***Department of Mechanical Engineering, University of Sciences and Technology of Oran, BP 1505 El -MNAOUER, \\ USTO 31000 ORAN, Algeria, E-mail: belhout.magi@gmail.com \\ **Laboratory of Science and Marine Engineering (LSIM), Department of Mechanical Engineering, University of Science \\ and Technology of Oran. BP 1505 El-MNAOUER, USTO 31000 ORAN, Algeria, E-mail: bouzit_mohamed@yahoo.fr \\ ***Ecole Superieur en Génie Electrique et Energétique ESGEE Oran, Algeria, E-mail: acer.msn@hotmail.fr \\ ****Faculty of Technology, University Hassiba Ben Bouali Ouled Fares, Algeria, E-mail: kamla_youcef@yahoo.com \\ *****Department of Technology, University Centre of Naama-Ahmed Salhi, Po. Box 66, Naama 45000, Algeria, \\ E-mail: ameur@cuniv-naama.dz
}

cross $^{\text {ref }}$ http://dx.doi.org/10.5755/j01.mech.26.3.24160

\section{NOMENCLATURE}

$L$ is length, $\mathrm{m} ; D$ is diameter, $\mathrm{m}$; $W$ is thickness, $\mathrm{m} ; p^{*}$ is step, $\mathrm{m} ; \mathrm{Z}$ is factor, /; $\Delta P_{M S}$ is pressure drop in static mixer, $\mathrm{Pa}\left(\mathrm{kg} \cdot \mathrm{m}^{-1} \cdot \mathrm{s}^{-2}\right) ; \Delta P_{T V}$ is pressure drop in empty tube, $\mathrm{Pa}\left(\mathrm{kgm}^{-1} \mathrm{~s}^{-2}\right)$; Re is Reynolds, /; $n$ is power index, /; $\tau$ is shear stress, $\mathrm{Pa}\left(\mathrm{kg} \cdot \mathrm{m}^{-1} \cdot \mathrm{s}^{-2}\right) ; \gamma$ is shear velocity, $\mathrm{S}^{-1} ; k$ is consistency index, Pa.s $\mathrm{s}^{\mathrm{n}}\left(\mathrm{kg} \cdot \mathrm{m}^{-1} \cdot \mathrm{s}^{\mathrm{n}-2}\right) ; V x$ is velocity axial, $\mathrm{ms}^{-1} ; T$ is Temperature, $\mathrm{K} ; Z^{*}$ is dimension less axial coordinate, $/ ; \mu$ is dynamic viscosity, $\mathrm{Kg} \cdot \mathrm{m}^{-1} \cdot \mathrm{s}^{-1}$.

\section{Introduction}

The static mixers (KENICS series) are used in the chemical, pharmaceutical and food industry. They contain helical elements that allow all mixing applications (turbulent, laminar, liquid-liquid dispersion, gas-liquid dispersion, extrusion, etc.), and characterized by the (lengthdiameter) ratio. These elements are made from thin and flat bands twisted at $180^{\circ}$ and placed inside a tube. The mixture quality is affected by several parameters such as the rheological behavior of the fluid, the internal diameter of the pipe, the number and shape of the elements and finally the flow velocity.

Some works have been achieved on the subject, among others; Hoobs et al. [1] used the Lagrangian method to study the effect of Reynolds number on the performance of the mixture in a laminar regime. Ghanem et al. [2] studied the mechanism, applications and methods of characterization of a static mixer. Regner et al. [3] tested numerically the influence of Reynolds number and the viscosity ratio of the mixed fluids (primary and secondary) on the mixing quality; they used the VOF method for the phase distribution. Song et al. [4] deduced numerically a correlation for the pressure drop in a static mixer with regard to Reynolds number $(R e)$, the friction factor and the aspect ratio of a mixing element (AR). Jaworski [5] used the two standard approaches (Eulerian \& Lagrangian) to simulate the laminar flow of two non-miscible fluids in a Kenics static mixer. The author showed that the standard models allow the prediction of the velocity distribution and mixing fractions but not the evolution of the drop size during the circulation of a mixture. Li et al. [6] studied by experiments the pressure drop of Newtonian and non-Newtonian fluids through a SULZER mixer (SMX). The study showed the effects of wall temperature, the nature of the fluid and the number of mixing elements. Annabelle et al. [7] studied the mixing efficiency in terms of pressure drop and mass transfer for a biphasic (gas/liquid) mixture in a SULZER mixer (SMX). Several configurations were studied, including the vertical upward position, vertical downward and horizontal with one, three and five elements of mixtures. Sinthuran et al. [8] conducted a comparative study between the experimental and numerical simulation to investigate the effects of the nature of secondary fluid and the speed ratio of the two fluids on the energy consumption in a SULZER mixer (SMX). Tian et al [9] introduced an improved technique that combines the transverse vibration with the rotation pitch in a Kenics (KM) static mixer. Rafiee et al. [10] used the method (PEPT), based on a Lagrangian fluid flow visualization to characterize the performance of the mixture of highly viscous Newtonian fluid. Hozumi et al. [11] used calcium hydrogels in a Kenics mixer to study the pressure drop, homogeneity degree as a function of the number of mixing elements, flow rate and Damkoler number $(\mathrm{DA}=$ residence time $/$ jellification time $)$. Meng et al. [12] simulated numerically the chaotic laminar flow in a modified Kenics mixer and they explored the effect of the aspect ratio, Reynolds number as well as the perforations design (diameter and spacing) on the friction coefficients, shear rates and the stretching rates. Mahammedi et al. [13] investigated numerically the performance of Kenics static mixer for stirring shear-thinning fluids. They focused on the effect of Reynolds number, fluid properties, twist angle and blade pitch on the hydrodynamics and pressure drop.

In the present paper, we explore numerically the flow of viscous fluids in a Kenics static mixer under laminar flow conditions. We investigate the effect of Reynolds number, fluid viscosity, aspect ratio $P^{*}$ and the number of mixing elements on the flow patterns and pressure drop.

\section{Presentation of the case studied}

The present case study is a cylindrical pipe with a length $L$ fitted with 8 fixed elements of a helical shape, where the length of these fixed elements is called the step $P^{*}$ [14]. The contact angle between two fixed elements varies between $0^{\circ}$ to $90^{\circ}$. Table 1 below summerizes the geometrical dimensions of the static mixer under investigation. 
Table 1 3.1. The drop pressure equation

Dimensions of the Kenics static mixer

\begin{tabular}{|c|c|c|c|c|}
\hline $\begin{array}{c}\text { Length } \\
L, \mathrm{~m}\end{array}$ & $\begin{array}{c}\text { Diameter } \\
D, \mathrm{~m}\end{array}$ & $\begin{array}{c}\text { Thickness } \\
W, \mathrm{~m}\end{array}$ & Angle $\alpha$ & Step $P^{*}$ \\
\hline 0.0762 & $1.5 \mathrm{~L}$ & $1 / 24 \mathrm{~L}$ & $90^{\circ}$ & $L / 6$ \\
\hline
\end{tabular}

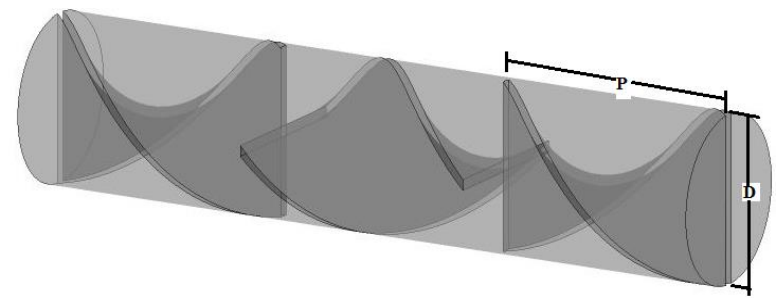

Fig. 1 Geometry of the problem studied

\section{Governing equations}

The numerical simulation was performed by using the CFX.12 computer software, which is which is based on the finite volume method. The fluid is assumed to be incompressible for an isothermal process with $R e$ values less than 100 (laminar flow). The governing equations are:

$$
\begin{aligned}
& \frac{\partial \rho}{\partial t}=-\nabla(\rho v), \\
& \frac{\partial(\rho v)}{\partial t}=-\nabla \cdot(\rho v)-\nabla p+\nabla \cdot \tau+\rho g+F,
\end{aligned}
$$

with: $\rho, p, v, g, F$ and $\tau$ are: the fluid density, pressure, velocity, gravity force and stress tensor, respectively. The boundary conditions are illustrated in Fig. 2.

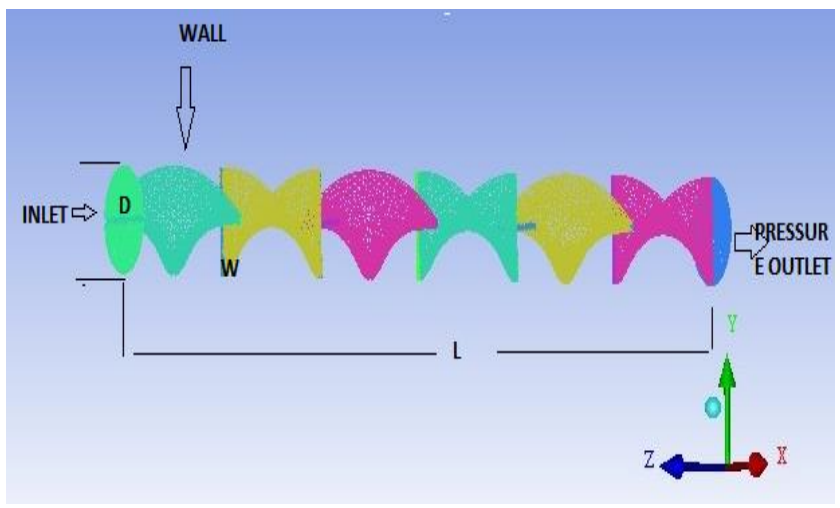

Fig. 2 Geometry mesh and boundary conditions

The fluid is rehological behavior is described by a power law [14]:

$$
\tau=k \gamma^{n}
$$

where: $n$ is the flow index $(0>n>1)$ and characterizes the behavior of the fluid.

$$
\eta=k \gamma^{(n-1)}
$$

where: $\eta$ is the viscosity.

The fluid is Newtonian for $n-1=0$ and in the other cases it is non-Newtonian.
This approach considers the relation $Z$ of the pressure drop in the static mixer $\Delta p_{M S}$ and the pressure drop in the empty tube $\Delta P_{T V}$ for a tube with the same diameter and the same length [15]:

$$
Z=\frac{\Delta p_{M S}}{\Delta P_{T V}}
$$

The factor $Z$ is a function of the mixer geometry and Reynolds number and it can be calculated by Eq. (6) for the laminar flow regime or Eq. (7) for the turbulent regime [16]:

$$
\begin{aligned}
& Z=\left(K_{O L}^{\prime} \times A\right)+K_{O L}, \\
& Z=K_{O T} \times B,
\end{aligned}
$$

where: the factors $A$ and $B$ are obtained according to $R e$ on graphs of the designer. Similarly $K_{O L}^{\prime}, K_{O L}$ and $K_{O T}$ are specific parameters according to the flow regime .

The pressure drop equation for a Kenics mixer is defined by the following correlation [17]:

$$
Z=7.19+\frac{R e}{32}
$$

The pressure drop for empty pipe $\Delta P_{T V}$ is calculated using the equation $[18,19]$ :

$$
\Delta P_{T V}=\frac{64}{\operatorname{Re}} \cdot \frac{L}{D} \cdot \frac{\rho \cdot V^{2}}{2} .
$$

For Newtonian fluid flow in pipe the Reynolds number is defined by:

$$
\operatorname{Re}=\frac{\rho \cdot v \cdot D}{\eta}
$$

where: $D$ is the pipe diameter.

\section{Boundary conditions}

Table 2

Boundary conditions of the Kenics static mixer

\begin{tabular}{|c|c|c|c|c|}
\hline Inlet & Outlet & $\begin{array}{c}\text { Cylindri } \\
\text { cal wall }\end{array}$ & $\begin{array}{c}\text { Helical } \\
\text { elements }\end{array}$ & Domain \\
\hline $\begin{array}{c}\text { Velocity } \\
\text { cst }\end{array}$ & $\begin{array}{c}\text { Pressure } \\
\text { outlet }\end{array}$ & Wall & Wall & $\begin{array}{c}\text { Fluid } \\
\text { domain }\end{array}$ \\
\hline Sobsonic & $\begin{array}{c}\text { Relative } \\
\text { pressure }=0 \\
\text { pa }\end{array}$ & $\begin{array}{c}\mathrm{V}_{\mathrm{WALL}}= \\
0 \mathrm{~m} \cdot \mathrm{s}^{-1}\end{array}$ & $\begin{array}{c}\mathrm{V}_{\text {WALL }}=0 \\
\mathrm{~m} \cdot \mathrm{s}^{-1}\end{array}$ & isotermal \\
\hline $\begin{array}{c}\text { Normal } \\
\text { speed }\end{array}$ & $\begin{array}{c}\text { Pressure } \\
\text { profile } \\
\text { blend=0.05 } \\
\text { pa }\end{array}$ & $\begin{array}{c}\text { Tempera } \\
\text { ture }=\mathrm{cst}\end{array}$ & $\begin{array}{c}\text { Tempera- } \\
\text { ture }=\mathrm{cst}\end{array}$ & $\begin{array}{c}\text { TFLUID }= \\
\mathrm{cst}\end{array}$ \\
\hline $\begin{array}{c}\text { Temperature } \\
=298^{\circ} \mathrm{K}\end{array}$ & $\begin{array}{c}\text { average over } \\
\text { whole } \\
\text { outlet }\end{array}$ & $/ /$ & $/ /$ & laminar \\
\hline
\end{tabular}




\section{Validation of results}

The mechanical energy dissipated in the helical mixer is obtained by determining the pressure drop $(\Delta P)$ between the outlet and inlet sections of the mixer.

The pressure drop across the mixer was determined as a function of Reynolds number variation (from 0.1 to 150). The obtained results are presented in Fig. 3. These results are in a good agreement with those of the literature given numerically by Saatdjian et al. [20].

A satisfactory agreement is also obseved between our predicted results and the correlation of Grace [21].

\section{Results and discussions}

After the validation our some predicted results, we studied the influence of several parameters on the flow structure and the pressure drop $\Delta P$ in this type of static mixer, namely: Reynolds number, fluid viscosity, aspect ratio $P^{*}$ and the number of fixed helical elements).

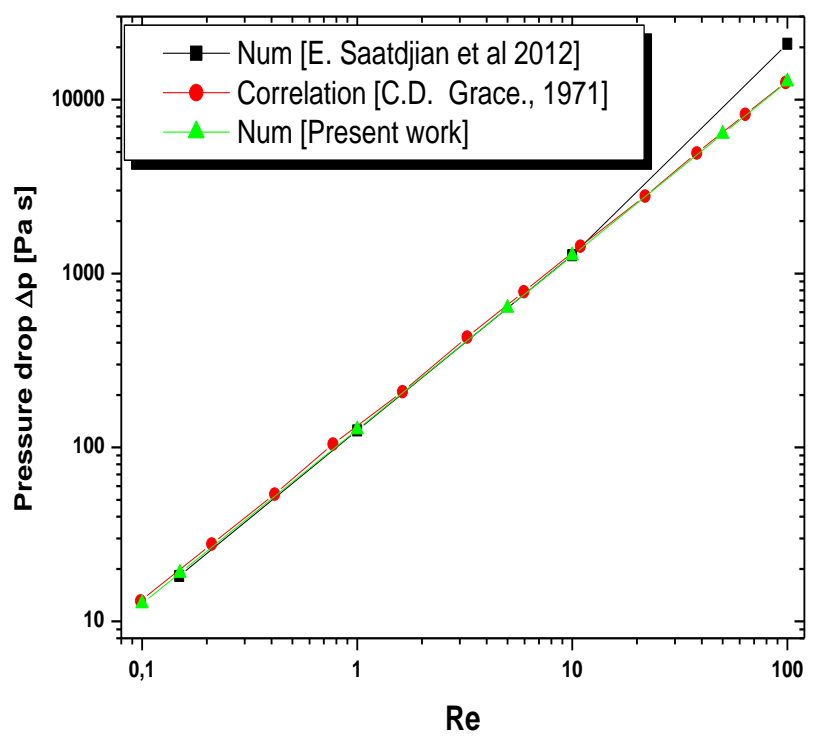

Fig. 3 Pressure drop versus Reynolds number

\subsection{Effect of Reynolds number}

Figs. 4 and 5 show, respectively, the axial velocity variation and the shear stress versus $Z^{*}$ along the static mixer. It must also be noted that the axial velocity is maximum at the mid-distance between the walls and the central axis of this mixer planes.

The variation of the pressure drop with respect to Reynolds number for different values of fluid viscosity is presented in Fig. 6. The pressure drop increases linearly with the increase of Reynolds number and the fluid dynamic viscosity. At low Reynolds number, the viscous forces of the fluid dominate the inertial forces. The globally the chaotic nature of the kenics static mixer. At low Reynolds number, we obtained an enhanced fluid stretching, which increased rate of diffusion.

Fig. 7 shows the effect of fluid viscosity on the variation of pressure drop $\Delta P$. According to this figure, the drop in pressure is inversely proportional to the fluid viscosity. We also notice that for water at a viscosity $0.000899 \mathrm{~Pa} \cdot \mathrm{s}$., the pressure exerted in the mixer would be less important compared to a fluid with viscosity $0.005747 \mathrm{~Pa} \cdot \mathrm{s}$. These results also indicate that this pressure takes the maximum values for the value of viscosity $0.005747 \mathrm{~Pa} \cdot \mathrm{s}$ and $\operatorname{Re}=100$.

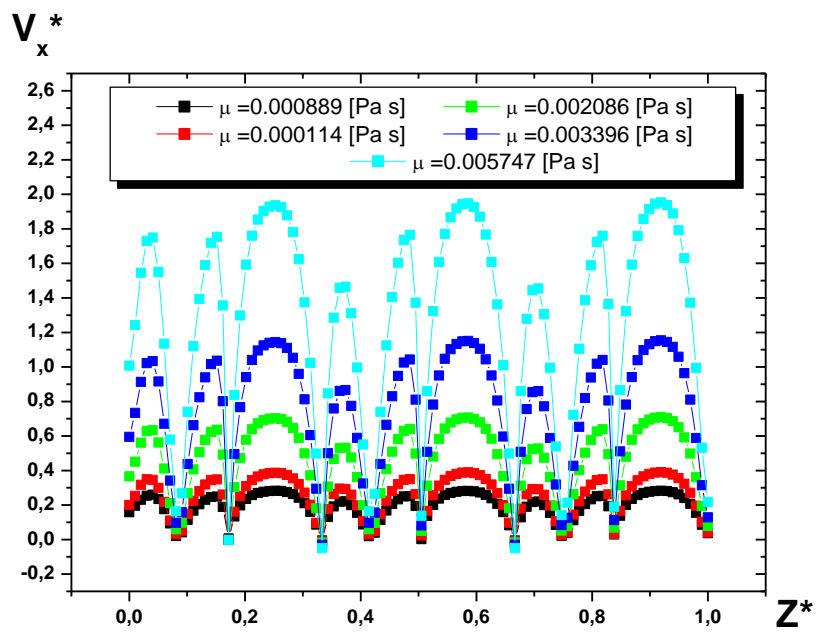

Fig. 4 Axial velocity versus $Z^{*}$ for $R e=50, r^{*}=0.0196$

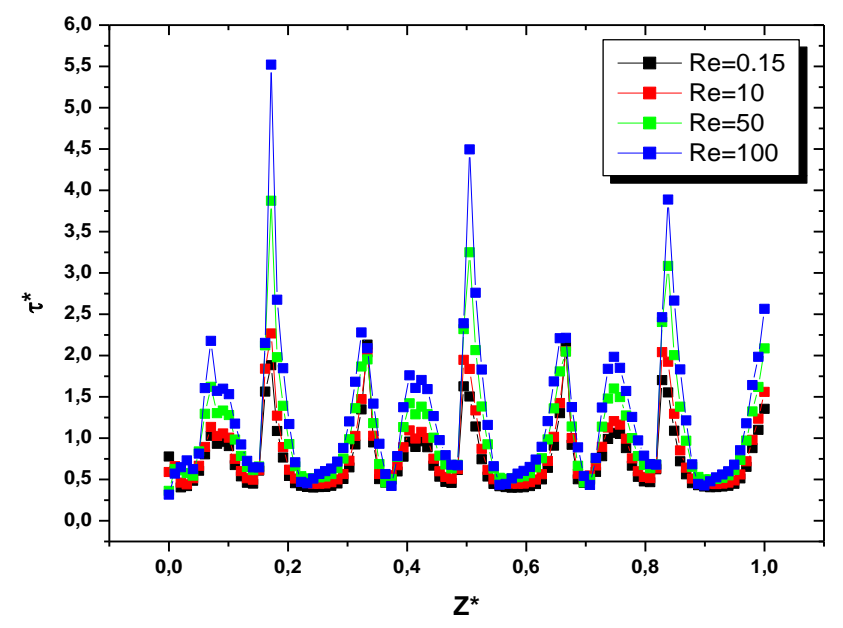

Fig. 5 Shear stress versus $Z^{*}$ for $\mu=5.747 \times 10^{-3} \mathrm{~Pa} \cdot \mathrm{s}$ and $r^{*}=0.0196$

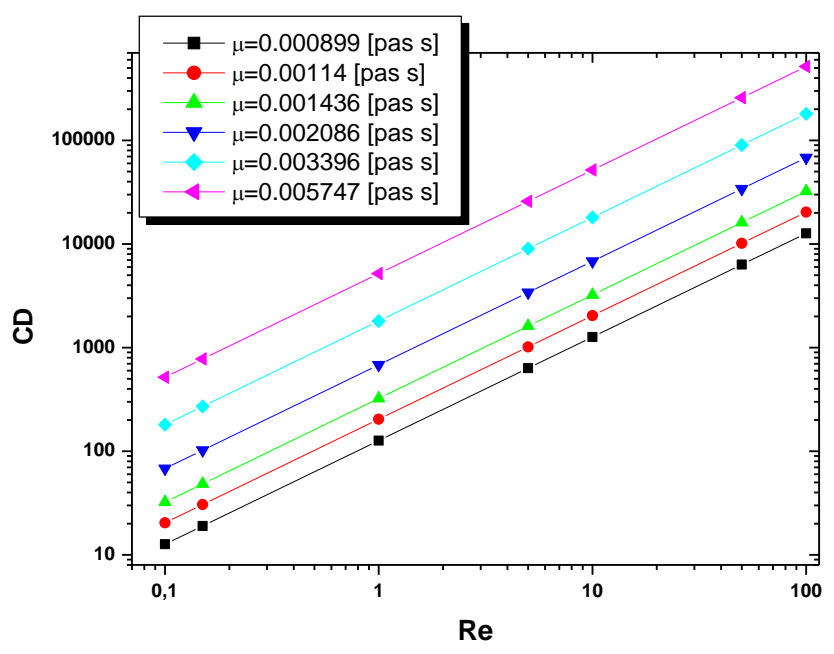

Fig. 6 Pressure drop versus Reynolds number for different fluid viscosity values

\subsection{The step effect (for $l=762 \mathrm{~mm}$ )}

In this section, we explore the effect of step of helocoidal elements. The different geometrical configurations realized are summarized in Table 2. Fig. 8 demonstrates the variation of the pressure drop as function 
of Reynolds number for different values of baffles number (steps) and $L / p$ (Table 3$)$. The pressure drop is increases linearly with the increase of the Reynolds number and the fluid dynamic viscosity.

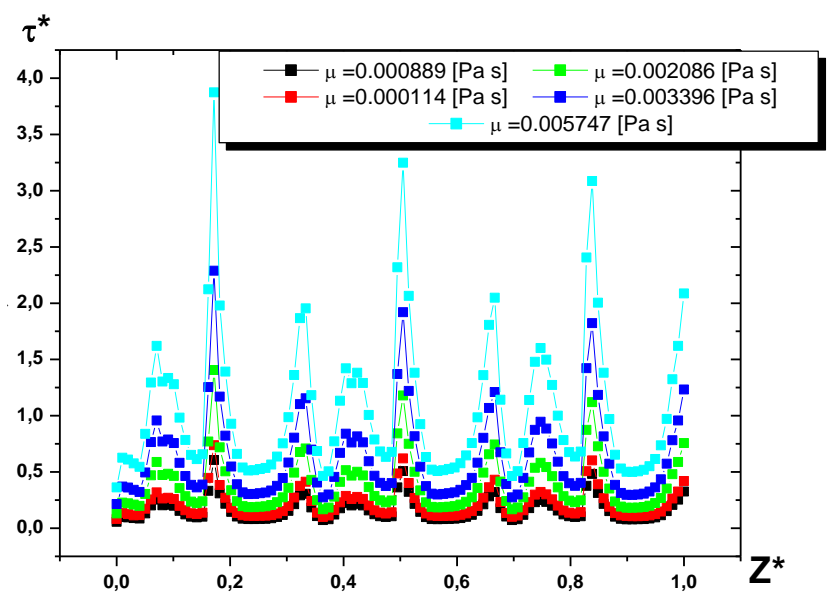

Fig. 7 Shear stress for $\mu=5.747 \times 10^{-3} \mathrm{~Pa} \cdot \mathrm{s}$ and $r^{*}=0.0196$

Table 3

Characteristics of the twisted elements of the standard kenics KM mixer

\begin{tabular}{|c|c|c|c|}
\hline Baffles number & 6 & 3 & 1 \\
\hline Step $(p)$ & 127 & 254 & 762 \\
\hline$L / p$ & $1 / 6$ & $1 / 3$ & 1 \\
\hline
\end{tabular}

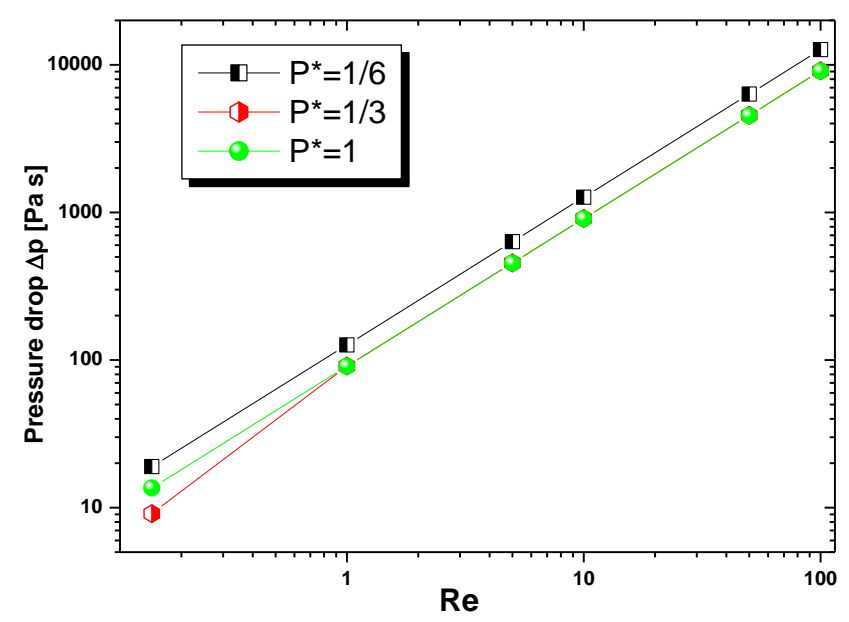

Fig. 8 Pressure drop across 1, 3 and 6 elements of the standard Kenics mixer

Fig. 9 shows the variation of the axial velocity along the mixer with different pitch values $\left(P^{*}=1,1 / 3\right.$ and $1 / 6)$. The maximum value of the axial velocity increases with the increase of the pitch value. The axial component of velocity is maximum at mid-distance between the walls and the central axis of this plane in the mixer $\left(X Y: Z^{*}=0.196\right)$. This gives rise to two symmetrical vortices in the cases $P^{*}=1$ and $1 / 3$ and four symmetrical vortices in the case $P^{*}=1 / 6$, as illustrated in Fig. 10 .

Fig. 11 shows the influence of the value of fluid temperature at the inlet section $\left(T_{\text {fluid }}=400\right.$ and $\left.450 \mathrm{~K}\right)$ onthe convective heat transfer through the static mixer (between the helical elements and the cylinder wall). This figure presents also the interaction between the fluid and the cylinder wall, as well as between the fluid and the static mixer element (forced convection).

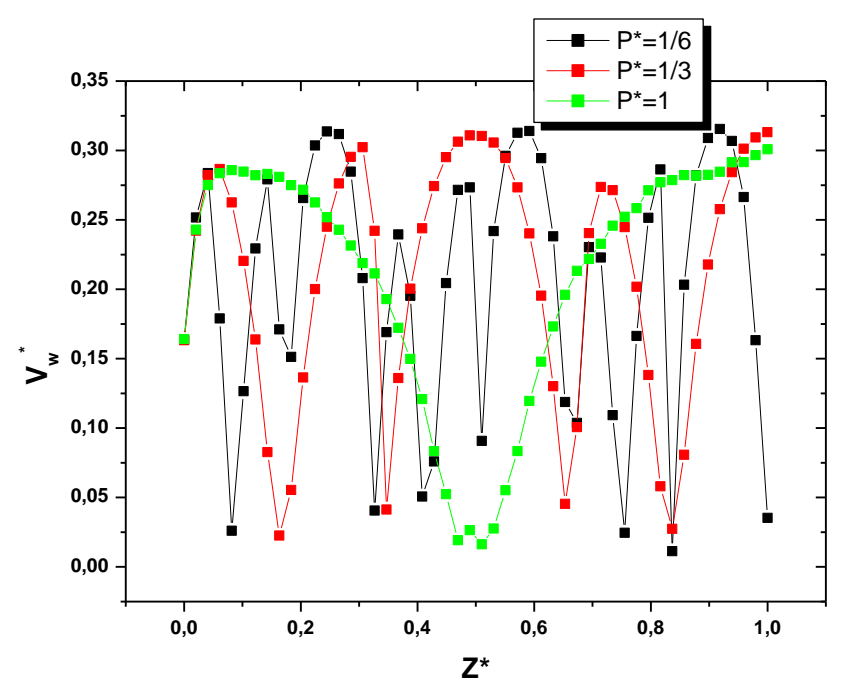

Fig. 9 Axial velocity along the mixer with different pitch ratios, at $R e=50, Z^{*}=0.196$
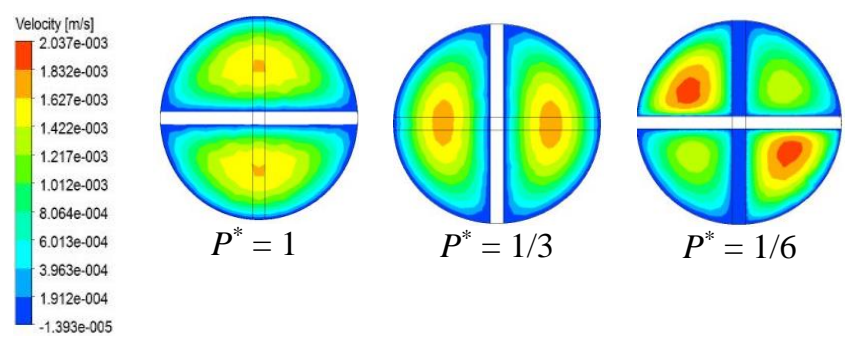

Fig. 10 Streamlines velocity for $R e=50, Z^{*}=0.5$

\section{The effect of inlet temperation}

In the last part of our study, we explore the effect of inlet temperation on the thermal fields within the Kenics mixer. We note the the temperature of the helical elements and the cylinder wall is fixed to $300 \mathrm{~K}$.

\begin{tabular}{l}
$4.50 \mathrm{e}+02$ \\
$4.43 \mathrm{e}+02$ \\
$4.35 \mathrm{e}+02$ \\
$4.28 \mathrm{e}+02$ \\
$4.20 \mathrm{e}+02$ \\
$4.13 \mathrm{e}+02$ \\
$4.05 \mathrm{e}+02$ \\
$3.98 \mathrm{e}+02$ \\
$3.90 \mathrm{e}+02$ \\
$3.83 \mathrm{e}+02$ \\
$3.75 \mathrm{e}+02$ \\
$3.68 \mathrm{e}+02$ \\
$3.60 \mathrm{e}+02$ \\
$3.53 \mathrm{e}+02$ \\
$3.45 \mathrm{e}+02$ \\
$3.38 \mathrm{e}+02$ \\
$3.30 \mathrm{e}+02$ \\
$3.23 \mathrm{e}+02$ \\
$3.15 \mathrm{e}+02$ \\
$3.08 \mathrm{e}+02$ \\
$3.00 \mathrm{e}+02$ \\
\hline
\end{tabular}
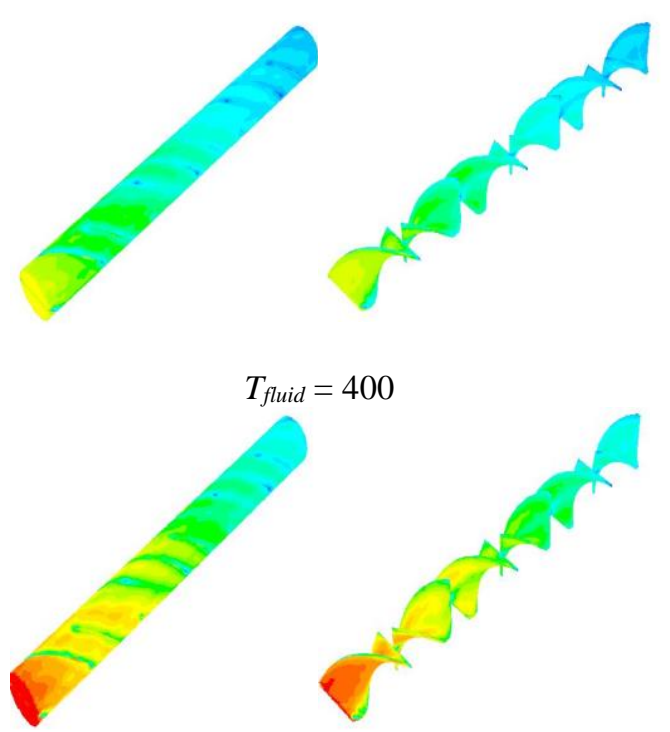

$$
T_{\text {fluid }}=450 \mathrm{~K}
$$

Fig. 11 The convective heat transfer for different values of fluid temperature 


\section{Conclusion}

In this paper, the study of viscous Newtonian fluids through a Kenics static mixer was performed via numerical simulation. The reliability of our results was checked by the comparison of the pressure drop as function of Reynolds number againt the numerical simulation of Saatdjian et al. [20] and the correlation of Grace [21] and a good agreement was observed. The comparison of velocity fields revealed clearly that the fluid viscosity and Reynolds number have an important impact on the performance of a static mixer. Intensified recirculation loops behind the twisted elements were observed with increaed Reynolds number and decreased fluid viscosity. The pressure drop was almost constant in spite of the modifications on the geometries such as the step and it increased with the raise of fluid viscosity.

For this kind of static mixers, further studies are needed reagarding the complex fluids with different rheological properties over a wide range of flow regimes and under heat conditions.

\section{References}

1. Hobbs, D. M.; Muzzio, F. J. 1998. Reynolds number effects on laminar mixing in the Kenics static mixer, Chemical Engineering Journal 70: 293-104. https://doi.org/10.1016/S0923-0467(98)00065-7.

2. Akram, G.; Lemenand, T.; Valle, D. D.; Peerhossain, H. 2014. Static mixers: mechanisms, applications, and characterization methods, Chemical Engineering Research and Design 92: 205-228. https://doi.org/10.1016/j.cherd.2013.07.013.

3. Regner, M.; Stergren, K.; Tragårdh, C. 2008. Influence of viscosity ratio on the mixing process in a static mixer, Numerical Study. Ind. Eng. Chem. 47: 3030-3036. https://doi.org/10.1021/ie0708071.

4. Song, H. S.; Han, S. P. 2005. A general correlation for pressure drop in a Kenics static mixer, Chemical Engineering Sciencce 60: 5696-5704. https://doi.org/10.1016/j.ces.2005.04.084.

5. Jaworski, Z. P.; Oprych, P. .2002. Two-phase laminar flow simulations in a kenics static mixer standard eulerian and lagrangian approaches, Chemical Engineering Research and Design 80: 910-916. https://doi.org/10.1205/026387602321143462.

6. Li, H. Z.; Fasol, C.; Choplin, L. 1997. pressure drop of newtonian and non-newtonian fluids across a sulzer smx static mixer, Chemical Engineering Research and Design 75: 792-796. https://doi.org/10.1205/026387697524461.

7. Annabelle, C.; Péculier, M. F.; Laplanche, A. 2008. Pressure drop and mass transfer study in static mixers with gas continuous phase, Canadian Journal of Chemical Engineering 80: 727-733. https://doi.org/10.1002/cjce.5450800426.

8. Jegatheeswaran, S.; Ein-Mozaffari, F.; Jiangning, W. 2018. Process intensification in a chaotic SMX static mixer to achieve an energyefficient mixing operation of non-newtonian fluids, Chemical Engineering \& Processing- Process Intensification 124: $1-10$.

https://doi.org/10.1016/j.cep.2017.11.018.
9. Shuai, T.; Barigou, M. 2015. An improved vibration technique for enhancing temperature uniformity and heat transfer in viscous fluid flow, Chemical Engineering Science 123: 609-619.

https://doi.org/10.1016/j.ces.2014.11.029.

10. Rafiee, M.; Bakalisa, S.; Fryer, P. J.; Ingram, A.. 2011. Study of laminar mixing in kenics static mixer by using Positron Emission Particle Tracking (PEPT), Procedia Food Science 1: 678-684. https://doi.org/10.1016/j.profoo.2011.09.102.

11. Hozumi, T.; Ohta, S.; Taichi, I. 2015. Analysis of the calcium alginate gelation process using a kenics static mixer, Industrial and Engineering Chemistry Research. https://doi.org/ 10.1021/ie5044693.

12. Meng, H.; Jiang, X.; Yanfang, Y.; Wang, Z.; Jianhua, W. 2017. Laminar flow and chaotic advection mixing performance in a static mixer with perforated helical segments, Korean Journal of Chemical Engineering 34: 1328-1336. https://doi.org/ 10.1007/s11814-017-0035-z.

13. Mahammedi, A.; Ameur, H.; Ariss, A. 2017. Numerical investigation of the performance of kenics static mixers for the agitation of shear thinning fluids, Journal of Applied Fluid Mechanics 10:989-999. https://doi.org/ 10.18869/acadpub.jafm.73.240.27314.

14. Wageningen, W. F. C.; Kandhai, D.; Mudde, R. F.; Akker, H. E. A. 2004. Dynamic flow in a kenics static mixer: an assessment of various CFD methods, AIChE Journal 50: 1684 - 1696. https://doi.org/ 10.1002/aic.10178.

15. Jegatheeswaran, S.; Ein-Mozaffari, F.; Jiangning. 2018. Laminar mixing of non Newtonian fluids in static mixers, Reviews in Chemical Engineering 2018: 1-14. https://doi.org/10.1515/revce-2017-0104.

16. Mochizuki, N.; Kaide, A.; Saeki, T. 2018. Quantitative evaluation of mixing characteristics of static mixers by visualization experiments, Journal of Flow Control, Measurement \& Visualization 06: 27-38. https://doi.org/10.4236/jfcmv.2018.61003.

17. Šereš, L.; Dokić, L.; Ikonić, B.; Simović, D. Š. 2017. Data-driven modelling of microfiltration process with embedded static mixer for steep water from corn starch industry, Perodica Polytechnica Chemical Engineering 62: $114-122$. https://doi.org/10.3311/PPch.10400.

18. Galaktionov, O. S.; Anderson, P. D.; Peters, G. W. M.; Meijer, H. E. H. 2003. Analysis and optimization of Kenics static mixers, International Polymer Processing Journal of the Polymer Processing Society 18: $138-150$. https://doi.org/10.3139/217.1732.

19. Armbruster, S.; Cheong, O.; Lölsberg, J.; Popovic, S. 2018. Fouling mitigation in tubular membranes by 3D-printed turbulence promoters, Journal of Membrane Science 554: 156-163. https://doi.org/10.1016/j.memsci.2018.02.015.

20. Saatdjiana, E.; Rodrigob, A. J. S; Mota, J. P. B. 2012. On chaotic advection in a static mixer, Chemical Engineering Journal 187: 289-298 https://doi.org/10.1016/j.cej.2012.01.122.

21. Grace, C. D. 1971. Static mixing and heat transfer, Chemical. Process. Engineerig, July, p. 57-59. https://doi.org/10.1063/1.4973327. 
C. Belhout, M. Bouzit, B. Menacer, Y. Kamla, H. Ameur

\section{NUMERICAL STUDY OF VISCOUS FLUID FLOWS IN A KENICS STATIC MIXER}

\section{S u m m a r y}

Since many years, the static mixers find usage in chemical, food, cosmetic and pharmaceutical industry. One of the most commonly used is the Kenics type static mixer. In a framework of the current work, the CFD simulations of Kenics static mixers were performed for viscous Newtonian fluids under laminar flow conditions. This simulation was made by using the computational fluid dynamic software (CFX 12.0). In this paper, we studied the influence of Reynolds number, fluid viscosity, aspect ratio and the number of helical elements on the flow patterns and pressure drop. It was found that the CFD results of pressure drop were similar to the literature data (the numerical simulation of Saatdjian et al. (2012) and the correlation of Grace (1971)).

Keyword: viscous fluid; Kenics static mixer; pressure drop; hydrodynamics; CFD simulations.

Received September 09, 2019 Accepted June 02, 2020 